ORIGINAL ARTICLE

\title{
Renal ultrasonography not required in babies with isolated minor ear anomalies
}

\author{
S A Deshpande, H Watson
}

See end of article for authors' affiliations

Correspondence to:

Dr Deshpande, Royal

Shrewsbury Hospital,

Mytton Oak Road,

Shrewsbury SY3 8 XQ, UK;

deshpande@which.net

Accepted

26 September 2005

Published online first

13 October 2005

\begin{abstract}
Aim: To determine whether infants with isolated minor anomalies of the external ear are at increased risk of renal malformations.

Methods: Consecutive infants with isolated minor anomalies of the external ear (preauricular skin tags, preauricular sinuses, ear pits, and misshapen pinnae) were offered renal ultrasonography by experienced sonographers over a 41 month period. The prevalence of renal anomalies in such infants was compared with that detected on routine fetal scanning during the same period.

Results: Ninety six of 13136 liveborn infants (7.3/1000, 95\% confidence interval (Cl) 5.9 to 8.9 ) were noted to have isolated minor ear anomalies on routine neonatal examination, with preauricular skin tags being the most common (85\%). Ninety one (95\%) infants underwent renal sonography at a mean (SD) age of 40 (19.6) days. Only one infant $(1.1 \%, 95 \% \mathrm{Cl} 0.03$ to 5.9$)$ had transient unilateral pyelectasia. During the same period, non-syndromic renal anomalies were found in $0.64 \%(95 \% \mathrm{Cl} 0.52$ to 0.73$)$ of infants, a prevalence no different from that of infants with minor ear anomalies $(p=0.44)$.

Conclusions: Routine renal imaging is not warranted in infants with such minor external ear anomalies unless accompanied by other systemic malformations.
\end{abstract}

M inor anomalies of the external ear are found in 5-10 per 1000 newborn infants, with preauricular skin tags being the most common. ${ }^{12}$ Whereas there is a general consensus about the need to search for renal malformations in babies with gross or syndromic ear abnormalities, ${ }^{3}{ }^{4}$ the need for such evaluations in infants with isolated minor ear anomalies is controversial. ${ }^{5}$ The published studies are generally underpowered, often lack appropriate controls, and have given variable results, sometimes even from similar sociodemographic populations. ${ }^{246-10}$ Moreover, none of the evaluations report on the frequency of any extra abnormalities detected by such sonographic surveillance on a background of now routine prenatal sonography.

We undertook this study to assess the yield of routine renal ultrasonography for detection of urinary tract abnormalities in infants with isolated minor external ear anomalies, in the era of routine fetal anomaly scanning.

\section{METHODS}

The study included all infants born at the Royal Shrewsbury Hospital between 1 May 2000 and 31 December 2003. Infants in whom isolated minor anomalies of the external ear (preauricular skin tags, preauricular sinuses, ear pits, and misshapen pinnae) were detected on routine neonatal examination were eligible for inclusion in the study. These infants were offered renal ultrasonography, in addition to hearing assessment, and cosmetic surgery referral. All the postnatal sonographic examinations were performed by a team of a consultant radiologist and three experienced ultrasonographers, who were unaware of the results of prenatal screening. Infants with initial abnormal scans underwent further imaging as clinically indicated.

During this period, a routine anomaly scan was offered to all pregnant women at around 20 weeks gestation. Fetuses showing renal abnormalities including pyelectasia $(>5 \mathrm{~mm}$ anteroposterior diameter in a transverse plane) were screened again at 32 weeks, and underwent postnatal renal sonography at 1 and 6 weeks of age. Further renal imaging studies were carried out as clinically indicated. We compared the prevalence of renal anomalies detected in infants with external ear anomalies with that found on routine prenatal sonography using the $\chi^{2}$ test. The study was approved by the local research ethics committee.

\section{RESULTS}

During the study period, 13136 infants were born at our hospital. Isolated minor anomalies of external ears were noted in 96 (7.3/1000 live births, 95\% confidence interval (CI) 5.9 to 8.9) during routine neonatal examination (table 1).

One infant moved out of the county soon after birth, and $91(95 \%)$ of the remaining eligible infants underwent renal sonography at a mean (SD) age of 40 (19.6) days after birth. The mean (SD) gestational age and birth weight of these infants were 39.5 (1.34) weeks and 3452 (508.4) g respectively. Forty two (46\%) were boys. Two infants had unilateral undescended testis, and one had glandular hypospadias.

The only renal abnormality found on abdominal ultrasonography was unilateral renal pelvic dilatation in one infant ( $1.1 \%, 95 \%$ CI 0.03 to 5.9$)$. The prenatal anomaly scan was unremarkable in this infant. There was no evidence of vesicoureteric reflux or pelviureteric junction obstruction on further imaging, and the pyelectasia resolved spontaneously by 14 months of age. Two other infants showed transient ovarian cysts.

During the same period, non-syndromic renal abnormalities were detected in 94 liveborn infants through prenatal screening $(0.64 \%, 95 \%$ CI 0.52 to 0.73$)$. These included renal pyelectesia $(\mathrm{n}=79)$, multicystic dysplastic kidneys $(\mathrm{n}=9)$, posterior urethral valves $(n=2)$, and polycystic kidney disease, bilateral renal hypoplasia, single kidney, and simple renal cyst in one infant each. The prevalence of renal abnormalities among infants with minor external ear anomalies was no different from that found on routine prenatal screening $(\mathrm{p}=0.44)$.

\section{DISCUSSION}

The prevalence of minor ear anomalies among the neonates in our study was similar to previous reports, ${ }^{12} 7811$ confirming these as relatively common congenital anomalies. We, 
Table 1 External ear anomalies

\begin{tabular}{llll}
\hline Nature of anomaly & $\begin{array}{l}\text { No of } \\
\text { infants }\end{array}$ & $\begin{array}{l}\text { No who had renal } \\
\text { sonography }\end{array}$ & $\begin{array}{l}\text { No with } \\
\text { normal scan }\end{array}$ \\
\hline Preauricular skin tags & 79 & 75 & 74 \\
$\quad$ Left & 43 & 41 & \\
Right & 28 & 26 & \\
$\quad$ Bilateral & 8 & 8 & 4 \\
Preauricular sinus & 4 & 4 & 6 \\
Preauricular pit & 6 & 6 & 4 \\
Misshapen pinnae & 4 & $4^{*}$ & 1 \\
Preauricular tags + misshapen pinna & 2 & $1^{*}$ & 90 \\
Preauricular sinus + tag & 1 & 1 & 91 \\
Total & 96 & 91 & \\
\hline *Hypoplastic ear (2), protruding ear (1), bilateral ear nodules with curled helices (1), prominent large ear with skin \\
tag (1).
\end{tabular}

\section{What is already known on this topic}

- Minor anomalies of external ears are relatively common in newborn infants

- There is controversy about the need for routine renal imaging in infants with such anomalies

however, did not find any significant increase in the prevalence of renal tract abnormalities in such infants. This finding is in accordance with three case series of infants with minor external ear anomalies, which found no increase in the incidence of renal malformations..$^{4612}$ The latter studies, however, were all of small size and lacked controls. In a prospective study from Israel, Kugelman et al found minor renal abnormalities in two of $92(2.2 \%, 95 \%$ CI 0.2 to 7$)$ infants with isolated preauricular skin tags or pits over four years compared with four of 95 control infants $(4.2 \%, 95 \%$ CI 1.1 to $10 ; \mathrm{p}=1.0$ ). On the other hand, another study from the same country detected renal abnormalities in six of 70 $(8.6 \%, 95 \%$ CI 2.2 to 12.4$)$ infants with isolated preauricular tags over seven years, compared with none (95\% CI 0 to 3.6 ) in a control group of 69 infants $(p<0.02) .^{7}$ In a study of 34 children (mean age at evaluation 4.7 years with only two neonates), three $(8.8 \%, 95 \%$ CI 0.6 to 8 ) had renal abnormalities. ${ }^{9}$ Neither of the latter studies, however, found any renal malformations in the control groups, unlike in the general population in which significant renal anomalies occur in $1.4 \%$ of infants. ${ }^{13}$ Leung and Robson ${ }^{2}$ found renal anomalies in three of $69(4.3 \%)$ infants with preauricular sinuses, but did not include any infant with preauricular skin tags.

The lack of excess renal abnormalities in our study is not surprising as embryonic development of the ears and kidneys occurs at different ages and at different rates. Any association between the abnormalities of these two organs is therefore unlikely to be due to a single insult but rather represents the effects of a common gene or a prolonged toxic insult. Increased frequency of clinically significant renal anomalies in association with ear malformations when the latter are a constituent of multiple congenital anomaly syndromes such as CHARGE association, branchio-oto-renal (BOR) syndrome, Townes-Brocks syndrome, or in diabetic embryopathy, supports this contention. ${ }^{4}$

In summary, our study provides incremental support to the notion that isolated minor anomalies of external ears are not associated with an increased risk of significant renal anomalies, and that routine postnatal ultrasonography is not required except when such anomalies are associated with other malformations.

\section{What this study adds}

- There was no significant increase in the prevalence of renal tract abnormalities in infants with isolated minor ear anomalies compared with that found on routine fetal sonography

- Routine renal ultrasonography is not warranted in infants with such minor anomalies unless accompanied by other systemic malformations

\section{ACKNOWLEDGEMENTS}

We thank Jenny Scott for help with collection of the data.

\section{Authors' affiliations}

S A Deshpande, Royal Shrewsbury Hospital, Mytton Oak Road, Shrewsbury SY3 8XQ, UK

H Watson, Department of Radiology, Royal Shrewsbury Hospital

Funding: none

Competing interests: none declared

\section{REFERENCES}

1 Ekelund H, Kullander S, Kallen B. Major and minor malformations in newborns and infants up to one year of age. Acta Paediatr 1970:59:297-301.

2 Leung AKC, Robson WLM. Association of preauricular sinuses and renal anomalies. Urology 1992;40:259-61.

3 Hilson D. Malformations of ear as a sign of malformations of genitourinary tract. BMJ 1957;2:785-9.

4 Wang RY, Earl DL, Ruder RO, et al. Syndromic ear anomolies and renal ultrasounds. Pediatrics 2001:e32.

5 Arora RS, Pryce R. Is ultrasonography required to rule out renal malformations in babies with isolated preauricular tags? Arch Dis Child 2004;89:492-3.

6 Hudgins L, Tuvale MK, Stephensen L. Isolated anomalies of the external ear are not associated with renal malformations. Proceedings of Greenwood Genetics Centre 1992;11:95.

7 Kohelet D, Arbel E. A prospective search for urinary tract abnormalities in infants with isolated preauricular tags. Pediatrics 2000:e61.

8 Kugelman A, Tubi A, Bader D, Chemo M, Dabbah H. Pre-auricular tags and pits in the newborn: the role of renal ultrasonography. J Pediatr 2002;141:388-91.

9 Mishra D, Archana, Gupta VK. Are isolated preauricular tags a marker of urinary tract abnormalities? Indian Pediatr 2003;40:796-7.

10 Bianca S, Ingegnosi C, Ettore G. Pre-auricular skin tags and associated anomalies: considerations for genetic counselling. Genet Couns 2003; 14:321-4.

11 Kankkunen A, Thiringer K. Hearing impairment in connection with preauricular tags. Acta Paediatr 1987;76:143-6.

12 Kugelman A, Hadad B, Ben-David J, et al. Preauricular tags and pits in the newborn: the role of hearing tests. Acta Paediatr 1997;86:170-2.

13 Steinhart JM, Kuhn JP, Eisenberg B, et al. Ultrasound screening of healthy infants for urinary tract abnormalities. Pediatrics 1988;82:609-14. 